\title{
Safety authority rebuts conflict claim
}

\section{Greens highlight industry links in bid to discredit European food agency.}

\section{BY DECLAN BUTLER}

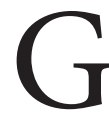
reen groups have long alleged that the European Food Safety Authority's (EFSA's) scientific risk assessments of food, animal feed and agrochemicals tend to be too industry friendly. But the criticisms intensified after last week's accusation of a conflict of interest at the very top of the organization.

On 29 September, José Bové, a French farmer and a representative of the Europe Ecology party in the European Parliament, alleged that Diána Bánáti - chair of the EFSA management board from October 2008 to 30 June this year - had failed to declare that in April 2010 she had joined the European board of directors of the International Life Sciences Institute (ILSI), a non-governmental organization that is funded by food companies and seeks to coordinate and fund research and risk assessment.

Bové provided no evidence that Bánáti's ILSI links had influenced her actions at EFSA, and the board has no direct role in the agency's risk assessments. EFSA points out that it has strict safeguards on conflicts of interest, but admits that the publicity over the affair risks harming public perception of its impartiality. Catherine Geslain-Lanéelle, EFSA's executive director, says that the agency has "learned lessons" from the recent attacks, and is considering introducing tougher rules for the chairs and vice-chairs of panels. "Public perception is important; we need trust," she says.

Bánáti is director general of Hungary's Central Food Research Institute in Budapest, and she remains on the EFSA board - a part-time post that is unpaid. EFSA says that the omission in Bánáti's declaration of interest - which was corrected last week — was an oversight on its part, and notes that ever since Bánáti joined the EFSA board in 2006, her membership of ILSI's scientific and advisory committee has been declared on EFSA's website.

Several other EFSA officials have links with
ILSI. For example, Milan Kováč, a prominent food scientist and government official in the Czech Republic, who is on the boards of EFSA and ILSI, is also a member of the scientific advisory board of the European Food Information Council, which is largely funded by food companies. Many EFSA scientific opinions also cite ILSI-sponsored studies.

ILSI insists that it is not a lobbying group. In a statement last week, the institute said that it seeks out top talent, and that it was "not surprising" that the same individuals are sought by other public-health bodies.

\section{CORRECTIONS}

In 'Science safe in Brazil elections' (Nature 467, 511-512; 2010) the graph should have read US\$ billions not US\$ millions.

In 'Brawl in Beijing' (Nature 467, 511; 2010), the correct link to Fang Shimin's website is www.xys.org. 